Approved for public release; distribution is unlimited

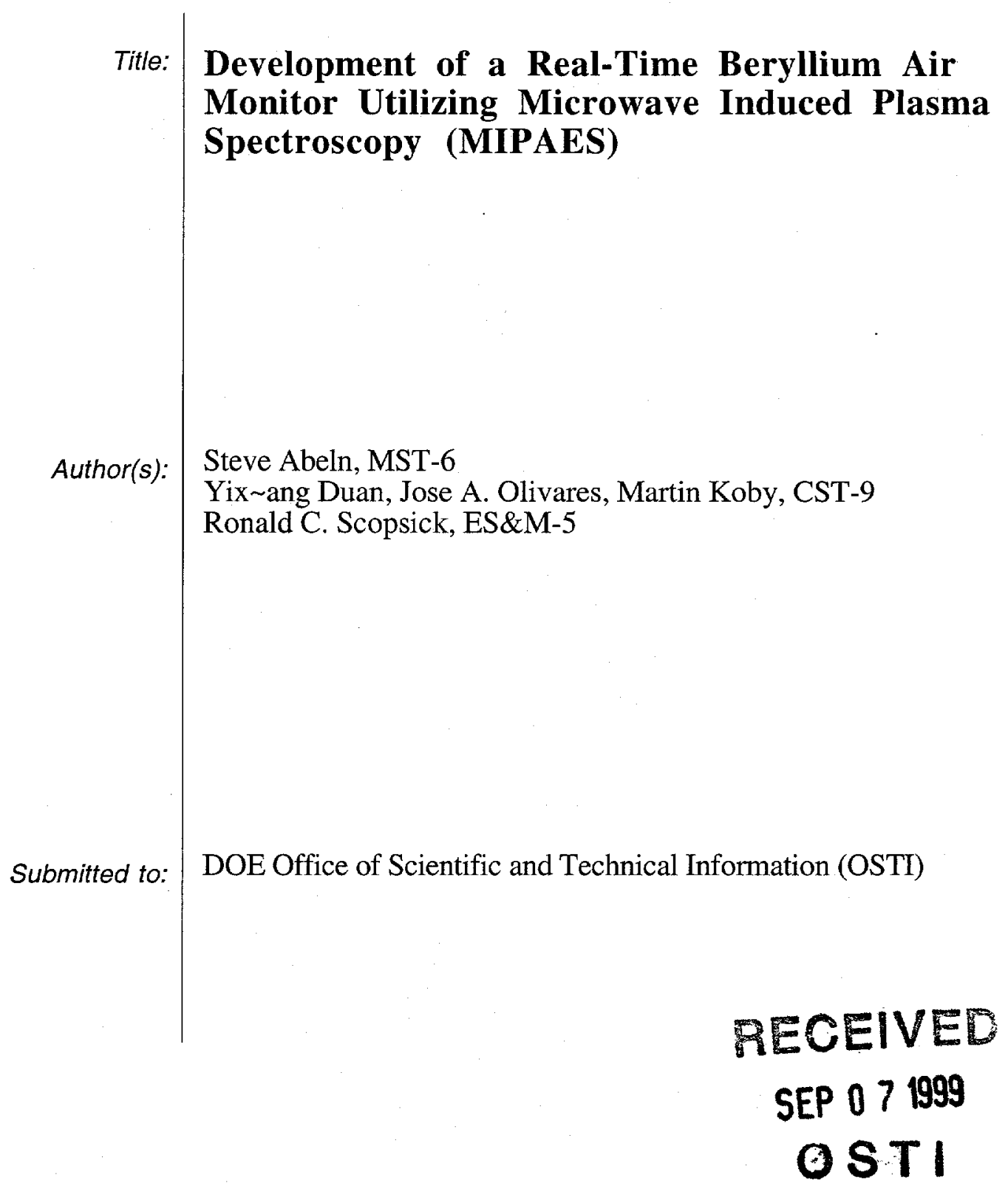

Los Alamos National Laboratory, an affirmative action/equal opportunity employer, is operated by the University of California for the U.S. Department of Energy under contract W-7405-ENG-36. By acceptance of this article, the publisher recognizes that the U.S. Government retains a nonexclusive, royaltyfree license to publish or reproduce the published form of this contribution, or to allow others to do so, for U.S. Government purposes. Los Alamos National Laboratory requests that the publisher identify this article as work performed under the auspices of the U.S. Department of Energy. Los Alamos National Laboratory strongly supports academic freedom and a researcher's right to publish; as an institution, however, the Laboratory does not endorse the viewpoint of a publication or guarantee its technical correctness. 


\section{DISCLAIMER}

This report was prepared as an account of work sponsored by an agency of the United States Government. Neither the United States Government nor any agency thereof, nor any of their employees, make any warranty, express or implied, or assumes any legal liability or responsibility for the accuracy, completeness, or usefulness of any information, apparatus, product, or process disclosed, or represents that its use would not infringe privately owned rights. Reference herein to any specific commercial product, process, or service by trade name, trademark, manufacturer, or otherwise does not necessarily constitute or imply its endorsement, recommendation, or favoring by the United States Government or any agency thereof. The views and opinions of authors expressed herein do not necessarily state or reflect those of the United States Government or any agency thereof. 


\section{DISCLAIMER}

Portions of this document may be illegible in electronic image products. Images are produced from the best available original document. 


\title{
Development of a Real-Time Beryllium Air Morutor Utilizing Microwave Induced Plasma Spectroscopy (MIPAES)
}

\author{
Steve Abeln* \\ Material Science and Technology, MST-6 \\ Yix ang Duan, Jose A. Olivares, and Martin Koby \\ Chemical Science and Technology Division, CST-9, MS K484 \\ Ronald C. Scopsick \\ Environmental Safety and Hygiene, ES\&M-5
}

\begin{abstract}
This is the final report of a one-year, Laboratory-Directed Research and Development (LDRD) Program Development project at the Los Alamos National Laboratory (LANL). The focus of this development has been an innovative beryllium air monitor for on-site' real-time continuous monitoring which overcomes limitations of the previous techniques for beryllium monitoring. A bench-top instrument has been set up and the performance of the instrument has been tested based on a solution aerosol. The sensitivity obtained with the instrument is sufficient to ensure workers can respond at airborne levels well below current exposure regulations. With this versatile, real-time monitor, worker exposure can be greatly reduced.
\end{abstract}

\section{Background and Research Objectives}

Background: Los Alamos has been selected by the DOE to be the site for beryllium (Be) technology within the complex and will be the only government controlled Be processing facility. The DOE has spotlighted the Be work in the Complex with its new rule-making and proposed Beryllium Worker Protection Program (BWPP). This rulemaking follows DOE's realization that previous Be health and safety programs within the industry have not been adequate. With over 100 diagnosed Chronic Beryllium Disease (CBD) cases in the Complex, DOE is showing a strong commitment to Be worker health and safety. CBD is the only occupational disease in the Complex that is actually making workers ill. The rule-making includes potential civil and criminal penalties that will make the University of California liable if the Lab is not in compliance. The University of California Presidents council on health \& safety has also shown interest in beryllium worker protection and the proposed new rule-making.

Currently, there are severe limitations in achieving a "0" CBD goal for the Complex. Exposure assessment is always "after the fact." Lapel and area monitoring is followed by chemical digestion to measure the exposure-a process that can take from two hours to two weeks. During

\footnotetext{
*Principal Investigator, e-mail: abeln@lanl.gov
} 
the sampling process, people use high volume samplers for beryllium measurements. The contaminated air is drawn through a Whatman filter paper at a high flow rate. Samples are collected from minutes to hours in the breathing zone and other work locations, and are then taken to a laboratory for analysis. This process does not lend itself to real-time analysis and amelioration of exposures. For these laboratory-based analysis procedures, appropriate sample handling, preservation and storage techniques have to be used to prevent sample loss, especially for high sensitivity and accurate analysis. Although laboratory staff have developed Laser Induced Breakdown Spectroscopy (LIBS) technique, which can be used for real-time monitoring, the technique is less sensitive, relatively expensive, and can not be run in a continuous mode. Based on these concerns and limitations, there is a clear demand to develop new instruments and strategies for beryllium monitoring.

Research objectives: The objective of this research was to develop a new portable instrument for on-site, real-time beryllium air monitoring. The new instrument required high sensitivity, compact structure, low cost, ease of operation, and in-situ sampling capability, which makes it possible for field inspection and site worker exposure monitoring. This new instrument will overcome limitations of the previous air monitoring techniques, and meet LANL and DOE's requirements.

\section{Importance to LANL's Science and Technology Base and National R\&D Needs}

Los Alamos has been assigned the beryllium technology mission within the DOE complex and will operate the only government controlled beryllium processing facility. The DOE has issued an interim notice (N440.1), Chronic Beryllium Disease Prevention Program, and is pursuing rule-making to provide stricter guidelines for beryllium worker protection. LANL and DOE are showing a strong commitment to Be worker health and safety. The University of California Presidents council on health \& safety is also committed to beryllium worker protection. The instrument developed here will provide sign)ficant improvement for beryllium exposure monitoring by providing timely information for site workers. Since the potential for new CBD cases in the DOE workforce will significantly impact LANL's beryllium technology mission assignment, a goal should be set up to achieve "0" CBD in the DOE Complex. This research project for developing an innovative beryllium air monitor for on-site, real-time monitoring is an important component to achieve " 0 " CBD.

This monitoring technique is broad, has many potential applications, and can be applied to almost all potential hazardous elements, such as the EPA controlled toxic or carcinogenic elements, $\mathrm{Ag}, \mathrm{As}, \mathrm{Ba}, \mathrm{Be}, \mathrm{Cd}, \mathrm{Cr}, \mathrm{Hg}, \mathrm{Ni}, \mathrm{Pb}, \mathrm{Sb}, \mathrm{Se}$, and $\mathrm{Tl}$. Because of its versatility, the instrument will have great potential for various applications at LANL and other DOE sites, and even for EPA routine environmental monitoring. Real-time monitoring can provide minute by minute pollution monitoring and therefore is likely to lead the current instrument development for environmental 
monitoring. Because this is a novel technique for air pollution monitoring, it's development should establish LANL's leadership role in this research field.

\section{Scientific Approach and Accomplishments}

Scientific approach: Microwave induced plasmas (MIP) are powerful sources for elemental analysis that have found extensive use in analytical atomic spectrometry. In this research, a high sensitivity microwave plasma technique has been utilized for beryllium exposure assessment, which overcomes limitations of the previous techniques for beryllium monitoring and analysis. Compared with other types of plasma sources, the MIP offers attractive characteristics such as, high excitation efficiency for both metal and nonmetal elements, capability of working with various gases including air, low complexity, and low cost. The microwave plasma can be operated in a continuous mode with various gases. This versatile, real-time monitoring can reduce worker exposure during beryllium operations by providing immediate feedback on airborne beryllium levels.

A newly developed microwave plasma torch (MPT) was utilized as an excitation source for atomic emission spectrometry (MPT-AES). The MPT discharges show excellent performance with gas sampling. The coaxial configuration of three tubes, similar to an ICP, offers some additional advantages over conventional microwave plasma sources. The flame-like plasma formed by the MPT has been demonstrated to be an excellent excitation source for emission spectrometry. Air or gas samples, including aerosols, are directly introduced into the MPT without pre-treatment. Maximum particulate transport into the plasma is therefore achieved. This design makes the instrument less complex, more compact and convenient for movement at work sites. The on-line system makes possible for in situ sampling similar to the laser spark techniques, but with much larger (several orders of magnitude) sampling volumes resulting in much higher sensitivity.

Accomplishments: During the time for this program development (one year), a bench top microwave plasma spectrometer/monitor was designed, machined, and assembled. This included building a microwave plasma torch, setting up a PC card spectrometer and a monochromater for optical beam collection and detection, and building a high eff ciency nebulization and desolvation system for sample introduction. Instrument testing and characterization included, optimization of the bench-top instrument, experimental parameter testing, optical fiber set-up, and improvements to enhance the system performance. Three ways, computer, mechanical, and chemical approaches, were explored to reduce background influence on analyte signals. The experimental results demonstrated that using the computer to subtract the background directly from the beryllium spectrum can significantly enhance detection sensitivity, while retaining the ability for real-time monitoring. With the PC card detection, a small beryllium signal has been obtained with 10 ppb sample solution and significant beryllium signals have been observed with $50 \mathrm{ppb}$ solution. In the current configuration, the detection limit of the instrument 
for beryllium is around $1 \mathrm{ppb}$ in solution or $0.11 \mathrm{~g} / \mathrm{m} 3$ in air. This is well below the current OSHA standard o $2 \sim \mathrm{g} / \mathrm{m} 3$ and the proposed DOE action level of $0.51 \mathrm{gg} / \mathrm{m} 3$. This instrument with its real time immediate feedback capability can ensure workers do not exceed the exposure limits. 


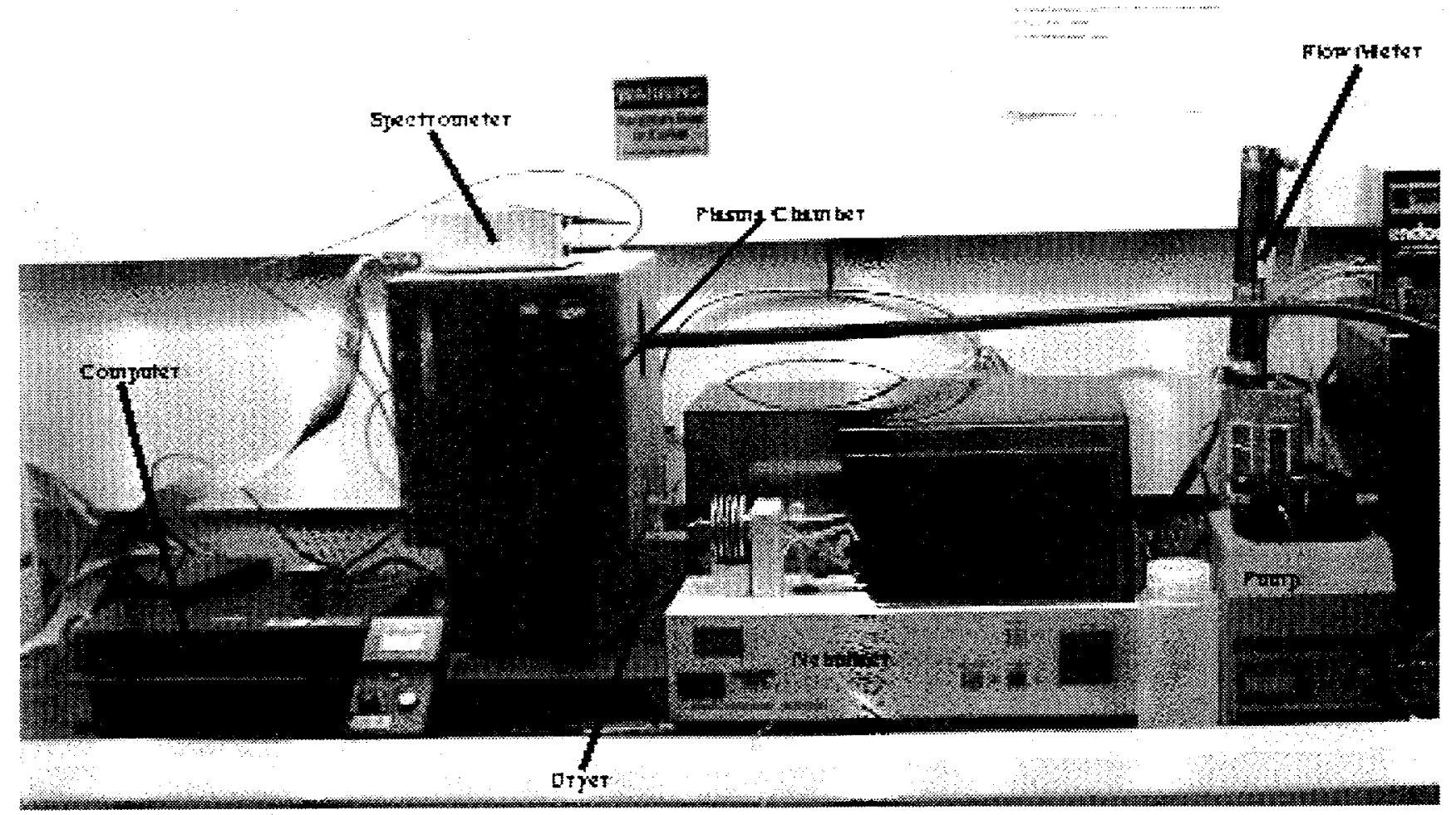

Figure 1: Bench-top instrument set up for beryllium monitoring. 


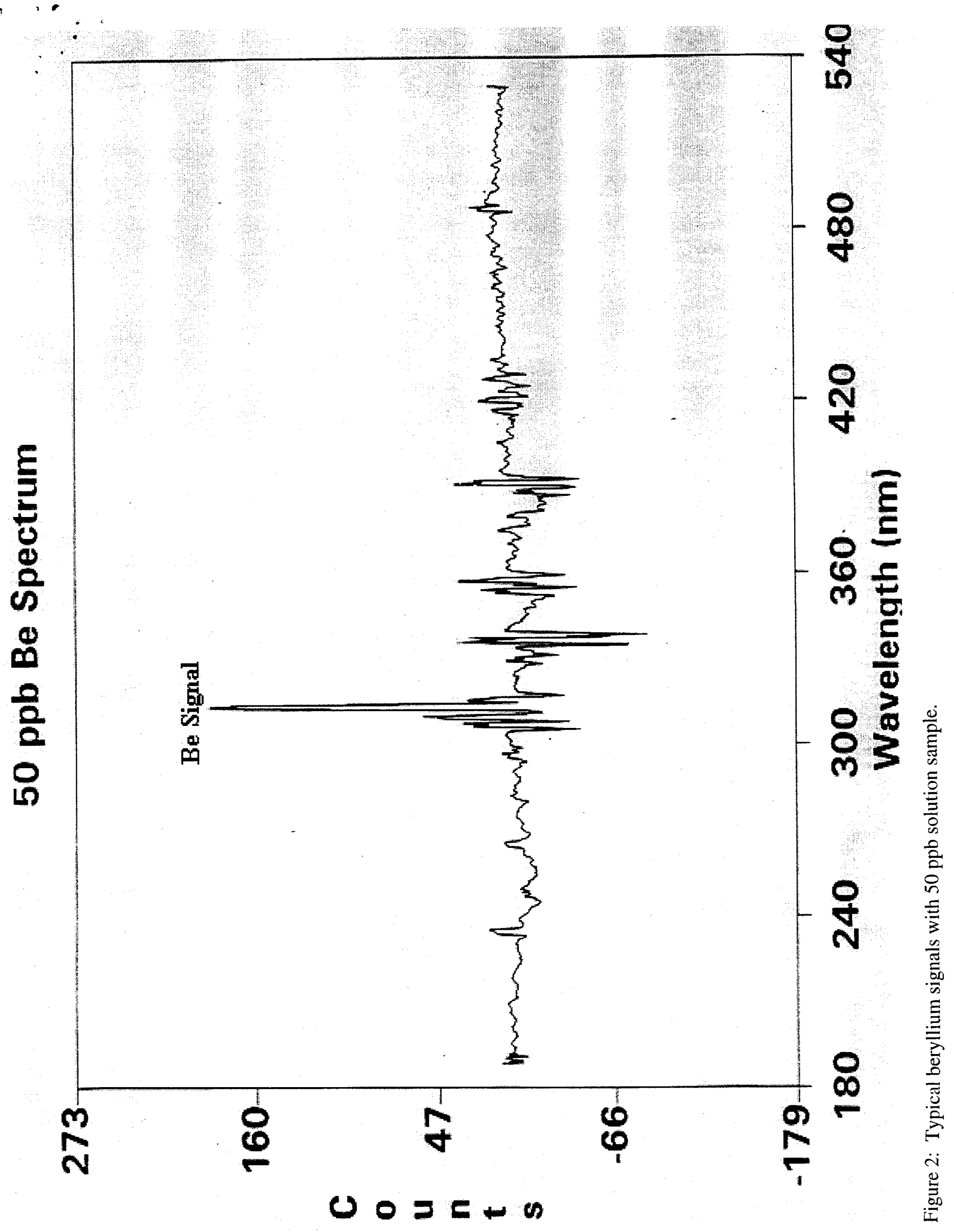

